\title{
A science-policy interface in the global south: the politics of carbon sinks and science in Brazil
}

\author{
Myanna Lahsen
}

Received: 14 February 2005 / Accepted: 10 March 2009 / Published online: 28 July 2009

(C) Springer Science + Business Media B.V. 2009

\begin{abstract}
The IPCC and other global environmental assessment processes stress the need for national scientific participation to ensure decision makers' trust in the associated scientific conclusions and political agendas. The underpinning assumption is that the relationship between scientists and decision makers at the national level is characterized by trust and interpretive synergy. Drawing on ethnographic research in Brazil, this article challenges that assumption through a case study of the policy uptake of divergent scientific interpretations as to whether or not the Amazon is a net carbon sink. It shows that the carbon sink issue became a site for struggles between important Brazilian scientists and decision-makers with central authority over the definition of the country's official position in international climate negotiations. In a geopolitically charged scientific controversy involving scientific evidence bearing on the Kyoto Protocol, Brazilian decision makers studied revealed critical distance from national scientists advancing evidence that the Amazon is a net carbon sink. As such, the decision-makers' interpretations were at odds also with dominant framings in the Brazilian media and closer to those of American scientists involved in carbon cycle research in the Amazon. Seeking to explain this disconnect, the paper discusses the divergent policy preferences of key scientists and decisionmakers involved, and the correlations of these preferences with interpretations of the available scientific evidence. It identifies the continued impact of a national political
\end{abstract}

Electronic supplementary material The online version of this article

(doi:10.1007/s10584-009-9610-6) contains supplementary material, which is available to authorized users.

M. Lahsen $(\bowtie)$

Center for Earth System Science, The National Institute for Space Research (INPE),

Av. dos Astronautas, 1758 - Jd. São José dos Campos, São Paolo 12227-010, Brazil

e-mail:myannal@gmail.com 
tradition of limited participation in decision making and suggests that this traditionwhile increasingly challenged by countervailing democratizing trends-is reinforced by key Brazilian decision makers' framing of science as a medium through which rich countries maintain political advantage. Reflecting this, key Brazilian decisionmakers dismissed national scientists' interpretations of the Amazon as a significant overall carbon sink by suggesting that the scientists' scientific training and associated foreign interactions bias them in favor of foreign interests, compromising their ability to accurately identify national interests. The paper situates its analysis in terms of theories of the science-policy interface and argues for greater attention to the role of culturally and politically laden understandings of science and the role of science in policy and geopolitics.

\section{Introduction}

"The LBA will orient decision making on forest policies," read the confident headline of an Amazonian news article (Província de Belém 1999) at the beginning of the Large-Scale Biosphere Atmosphere experiment in Amazonia (LBA). The largest program in international scientific cooperation ever focused on the region and the largest global change science project to ever take place in Brazil, the LBA aims to enhance knowledge of ecological processes in the Amazon related to global environmental change. The creation of the LBA reflected LBA leaders' perceived need for progress in global carbon $\left(\mathrm{CO}_{2}\right)$ cycle science in order to better inform international negotiations and policies related to the global environment in general, and climate change in particular (LBA Science Planning Group 1996). Moreover, Brazilian scientists and some science administrators in Brazil hoped that new scientific information might prompt sustainable national- and regional-level policies and practices in and for the Amazon.

Five years later (July 2004), LBA leaders organized a meeting in Brasília to engage the latter in discussions about the role of science in national policymaking concerning the Amazon region, with particular focus on the scientific contributions of the LBA. The event reflected recognition of the limited impact of LBA research on federal environmental decision-making. ${ }^{1}$ The number of policy-makers who attended the event was much smaller than hoped. With few exceptions, those who participated stayed only long enough to attend their short, specific panels.

The gap between the ambitions for the LBA and its actual policy impact supports the well-established insight that uncertainties justify inaction when it serves powerful political and economic agendas, and that scientists often communicate ineffectively with decision makers (Schneider 2000). However, understanding the science-policy interface in Brazil — around this issue and more generally-requires understanding (1) the particular, complex relationship between science and Brazilian scientists,

\footnotetext{
${ }^{1}$ One of the forums for such discussions was the 16th Meeting of the LBA's Scientific Steering Committee in Manaus, 4-6 November 2004. Discussions among LBA leaders in various forums about the continuation of the LBA in its second, post 2005-phase reflected this recognition as well, along with desires to change this state of affairs in the future.
} 
on the one hand, and national decision makers in Brazil with power over climaterelated affairs on the other, and (2) that the sink issue involves a larger struggle to define Brazilian interests in international climate negotiations, especially as related to deforestation.

On the basis of empirical research spanning 10 years (1999-present) among Brazilian scientists, science administrators, activists, and decision makers involved with climate change, ${ }^{2}$ this paper draws out implications of the insights from this case study for theories of the science-policy interface. It relates scientific and political divisions on the carbon sink issue to geopolitical divisions under the United Framework Convention on Climate Change and, within Brazil, to a struggle to define national interests related to climate change and deforestation in the Amazon. It pays particular attention to Brazilian scientists' and decision makers' varied interpretations of a subset of findings produced under the LBA related to whether or not the Amazon is a carbon sink-that is, whether the undisturbed Amazon forest functions as a net absorber of carbon (hereafter referred to as the 'pro-sink' argument), or whether the region is more or less 'carbon neutral,' roughly emitting through respiration as much carbon as it absorbs through photosynthesis (hereafter referred to as the 'no-sink' position). The paper limits its scope to the question of $\mathrm{CO}_{2}$ balance, excluding discussion of how methane emissions from natural estuaries and human-made reservoirs contribute to the overall greenhouse gas profile, as well as the role of $\mathrm{N}_{2} \mathrm{O}$ soil fluxes.

The paper concludes that while LBA scientists disagree on the amount by which the Amazon forest absorbs more carbon than it releases, and disagreed especially strongly during the period in focus, i.e., the first half of the 2000s, Brazilian scientists and media-rightly or wrongly—consistently privilege evidence suggesting that it is a large carbon sink and harness this evidence to a particular conception of the national interest in favor of forest conservation.

The central year in focus is 2002, when the majority of the interview- and media data was collected, and a point at which the disagreement among scientists was higher than in more recent years. However, the article includes data up until 2009 and identifies long-standing and continuing trends in the science-policy interface in

\footnotetext{
${ }^{2} \mathrm{~A}$ total of 70 semi-structured interviews were conducted among Brazilian, European and American LBA-involved scientists and science administrators, and among Brazilian decision makers in the Ministries of Science and Technology, External Relations and the Environment. The interviews probed opinions about the LBA as well as interpretations of carbon cycle science related to the Amazon and associated politics at the national and international levels. Interviews with Brazilian decision makers also probed relationships between various parts of the government. The author has performed anthropological research focused on climate scientists and climate politics in the USA since 1994. For results from this research, see Lahsen (1999, 2005a, b). Following an initial round of fieldwork in Brazil in 1999, she has been residing and doing research there since 2002, focusing on Brazilian participation in international environmental science and policy initiatives related to human-induced climate change. The research has consisted mainly in semi-structured interviews, supplemented by participant-observation when possible. The research on the LBA also mapped patterns of difference among American, European and Brazilian scientists on the issue of the Amazon's role in the global carbon cycles and associated policy implications.
} 
Brazil (for more on the representativeness of the data and analysis, see supplementary on-line documentation \#1); as in any country, political culture and institutions shaping the science-policy interface in Brazil have deep historical roots and are slow to change.

That said, Brazil's political culture is marked by two conflicting strands. One is authoritarian and the other democratic in nature, with the latter being newer and less securely institutionalized (Wiarda and Kline 2000). As I discuss further below, the authoritarian, insular and centralized approach to decision-making related to climate change is increasingly challenged by the more democratic strand. This analysis of the climate science-policy interface in Brazil reveals that the authoritarian strand of Brazil's political culture has nevertheless dominated the country's climate policy up until the present, and that the decision makers perpetuating this anti-democratic strand in Brazilian climate policy processes legitimize this on the basis of constructions of science as a political tool favoring hegemonic countries' narrow interests. More specifically, Brazilian decision makers in institutions oriented towards minimization of international interference with land management in the Amazon showed themselves aversive to scientific interpretations of the region as a carbon sink, and explained this aversion partly through interpretations of national scientists as victims of the manipulations of foreign powers.

To the extent that environmental scientists and activists are central to the advancement of democracy and environmental policy in Brazil (Chandler 1998; Guimarães 1991, 2002; Mumme and Korzetz 1997; Viola 2004a, b; Wiarda and Kline 2000), the here identified distance between them and key national environmental policy makers tends to constitute a general obstacle to advances in these areas. That said, in this case, the interviewed decision-makers who maintained such critical distance and defended the government's official position against compensation of avoided deforestation justified their position on an environmental argument, arguing that a policy mechanism compensating avoided deforestation was ineffective and undermined the purpose of the Kyoto Protocol, namely reduction of greenhouse gas emissions.

\subsection{Contributions}

This study conceives science as inextricably interlinked and "co-produced" (Jasanoff and Wynne 1998; Jasanoff 2004) with politics rather than separate from it, as held by classical and neo-classical understandings of the role of science in policy. The co-productionist framework-like most strands of social constructivism, despite the unfortunate connotations of the latter-does not imply that science 'makes up' nature unrestrained by empirical reality, nor that nature is determined by social factors alone (Jasanoff 2004). Rather, the co-productionist framework, and the strand of constructivism that it integrates, conceives of scientific issues as inherently linked to-and reflecting - a much wider set of socio-cultural and political issues and debates, and acknowledges the role of meaning-making, trust, credibility, power and control in both its production and use. This framework stresses the need for 'thick descriptions' and analysis of particularities of context to understand environmental politics and policy outcomes, including the role of science in them.

This study offers insight into particularities shaping the science-policy interface in Brazil. It addresses knowledge gaps in the scholarly literature through a focus on political and cultural factors shaping policy makers' receptivity to various types of 
knowledge in this less developed country context. Even in the area of environmental decision making, where science figures so importantly, there continues to be 'surprisingly little research that identifies how ecological information and scientists actually contribute to, or participate in, decision processes involving natural resources, and how their scientific and normative judgments affect the policy process' (Steel et al. 2001, p. 137. See also McNie 2007). A sanitized picture of the science-policy relationship dominates the literature on global environmental politics and policy. It posits scientists as policy-disinterested providers of objective knowledge who speak with one voice, and decision makers as earnest truth-seekers who understand and look to science as a neutral, non-politicized source of knowledge (Lahsen 2007; Lahsen and Öberg 2006). Findings to the contrary, such as those presented here, expose a nuanced but more complex reality that is best understood not as corruption and aberration but as the norm, especially in areas of 'post-normal' science (Funtowicz and Ravetz 1992) characterized by high scientific uncertainty and high socio-political and environmental stakes. This understanding is reconcilable with a view of science as a fallible but particularly rigorous and powerful means of producing robust knowledge about the world (Lahsen 2005b). ${ }^{3}$

Finally, the study counters the tendency for models of the science-policy interface to ignore historical and structural influences on agenda setting and to attend little to the impact of science, including its role in consolidating or overcoming bias in policy issue selection (Jasanoff and Wynne 1998). Environmental decision making in the global South is especially understudied (Steinberg 2001), and even more so the role of science and associated perceptions in it. ${ }^{4}$ (For more on contributions and the coproductionist model by comparison to classical models of science, see supplementary on-line information \#2).

Findings presented here also expose the insufficiency of scientific participation as a means of securing decision makers' trust in science-laden political processes insofar as they reveal that synergy between national scientists and decision makers is less automatic than often assumed. Moreover, to the extent that Brazilian decision makers base their distrust of national scientists on the influence of foreign hegemonic influences, there may be particular reasons for disconnect between science and policy in less developed countries because of developed countries' scientific dominance.

\section{The large-scale biosphere atmosphere experiment in Amazonia (LBA)}

\subsection{Beginnings}

Environmental scientists conceived of the LBA, which came to involve collaboration predominantly among scientists and institutions in Brazil, the USA and

\footnotetext{
${ }^{3}$ For theories of how new global environmental threats impact the nature of scientists' knowledge and engagements, see the literature by reflexive modernization theorists (Beck 1992; Beck et al. 1994; Lash et al. 1996). For empirical studies illustrating how extra-scientific factors affect scientists' engagements in these issue areas, see Lahsen (1999, 2004, 2005a, b, 2008), Lahsen and Nobre (2007), Litfin (1994). See also Demeritt $(2001,2006)$.

${ }^{4}$ The otherwise excellent book edited by MacDonald and Stern, Latin American Environmental Policy in International Perspective, exemplifies this lack of attention to science; its index does not even mention the word 'science.'
} 
Europe, with an annual budget of around US\$ 12-15 million between 1998 and 2004. ${ }^{5}$ The LBA received financial support for a major part of the associated field experiments and infrastructure development from the US National Aeronautics and Space Administration (NASA) and the European Union. The largest part of the direct funding for field research came from NASA, which dedicated about US\$6 million to the LBA. Direct funds from the Brazilian government were fewer but, by some estimates, Brazil indirectly contributed a roughly equal amount. ${ }^{6}$

The LBA grew out of three plans and associated "discussion groups:" LAMBADA (Large-Scale Atmospheric Moisture Balance using Data Assimilation), BATERISTA (Biosphere-Atmosphere Transfer and Ecological Research In situ Studies in the Amazon) and AMBIACE (Amazon Biology and Atmospheric Chemistry Experiment), respectively dominated by physical climate scientists, hydrologists, and biogeochemists and atmospheric chemists. NASA's involvement was concentrated in the last two groups, while European scientists were concentrated in the first two. By 1996, the foundational experimental plans were drafted and the separate US and European collaborations with Brazilian scientists consolidated.

The growing concern about tropical deforestation combined with the following factors to make the collaboration interesting to leaders in NASA's environmental science division: (1) advances in satellite technology facilitating detection of deforestation; (2) NASA's institutional emphasis on remote sensing technologies; (3) the fact that Brazil was the only country gathering extensive satellite information of deforestation; (4) NASA's previous history of collaboration with Brazil and with INPE, in particular, the Brazilian institution with central oversight over the LBA during its first years. Moreover, US science agencies were seeking to boost understanding of carbon storage mechanisms with view to manipulating a significant part of the globe's biomass as a strategy to deal with human-induced climate change (Fogel 2004). ${ }^{7}$

\footnotetext{
${ }^{5}$ Those were the years of the program's most intensive field campaigns. The LBA's first phase began in 1998 ended at the end of 2006, marked by a final intensive field experiment to calculate regional budgets of carbon for Amazônia (the BARCA experiment). NASA continued to support collaborative synthesis activities through 2008. Since LBA is a Brazil-led project, it is up to Brazil when it ends. In late 2004, the Brazilian government introduced plans to continue the LBA past its first phase but as a national program in which foreign scientists would participate in a more limited fashion, and only at the invitation of the Brazilian Ministry of Science and Technology. LBA activities waned significantly as a function of the changes in administration and organization and associated weakened and uncertain funding conditions. There is general consensus among LBA scientists at the time of the transition that due to thee above factors, the LBA, as they had known it so far, ended in 2006.

${ }^{6}$ NASA has contributed a total of about US $\$ 6$ million. However, while this figure includes overhead charges, salaries and scholarships to US institutions and scientists, Brazil's direct financial contribution does not. Adding Brazil's contributions in the form of facilities made available to the LBA, salaries of LBA-involved Brazilian scientists, and federal and state-level student scholarships, it has contributed over half of the total LBA budget, according to Carlos A. Nobre, Senior Scientist, Brazilian Center for Weather Forecasting and Climate Studies, INPE (interviewed in Cachoeira Paulista, São Paulo, Brazil, 17 February 2003).

${ }^{7}$ Fogel (2004) cites a 1999 report by US Department of Energy which called for the intensive management and/or manipulation of a significant fraction of the globe's biomass to deal with the challenge of climate change.
} 
UK-Brazilian environmental research under ABRACOS (the Anglo-Brazilian Amazonian Climate Observation Study, ${ }^{8}$ 1990-1996) lead up to the LBA. ABRACOS reflected European political interest in improved dialogue and relations with Brazil and in more knowledge about environmental issues in the Amazon at a time of growing concern about deforestation. When looking for LBA research funds from the European Union (EU), European scientists argued that the research was in the EU's self-interest because Amazonian environmental dynamics could impact Europe due to the Amazon's size and position in the tropics. This resulted in EU funding of a project, the initially proposed title of which included the term "carbon sink." Many saw this title as a reflection of European scientific and political bias, and judged the title to inappropriately presume discovery of a carbon sink in the Southern Hemisphere. The title was subsequently changed.

Despite heated discussion and internal disagreement, two key features secured the approval of the LBA at a closed meeting of a handful of top-level ministers convened by then President Fernando Henrique Cardoso: the scientific capacity the LBA promised to build and the new knowledge it could yield about Amazonian ecosystems. The LBA was never subjected to Congressional approval, which provoked a law suit and sustained considerable resistance to the LBA within the Brazilian government and beyond, spurred by suspicions that the LBA served foreign economic and political interests in the Brazilian Amazon and its natural resources. Fears of biopiracy are widespread in Brazil. While supported by real life incidents, such fears remain unsubstantiated in the case of the LBA.

\subsection{The science and its policy implications}

Focused primarily on the Brazilian Amazon region, LBA science has yielded a wide array of findings related to this region, ranging from basic natural science to estimates of the environmental impacts of Brazilian development plans (Laurance et al. 2001) and how to minimize social and environmental damage from development projects (Brown et al. 2002). Supplementing emerging knowledge about the role of Northern hemisphere forests in the global carbon cycle with knowledge about tropical forests, the larger part of research efforts under the LBA probed the links between global environmental change and Amazonian land use changes, including the functioning of the region as a biogeochemical system and the sources and levels of Brazil's greenhouse gas emissions.

The greenhouse gas emissions from tropical forests due to natural or humaninduced processes are not well defined and constitute one of the largest sources of uncertainty in present understanding of the global carbon budget (Potter et al. 2001; Defries et al. 2002; Persson and Azar 2004). About half of the carbon dioxide humans emit through fossil-fuel combustion and land-use change does not reach the atmosphere. The oceans are calculated to absorb about $40 \%$ of this carbon 'missing' from the atmosphere. Scientists are generally convinced that the remainder is absorbed by the terrestrial biosphere, especially forests. However, this is difficult

\footnotetext{
${ }^{8}$ ABRACOS studied Amazonian climate and the consequences of deforestation, and provided data for the calibration and validation of GCMs and GCM sub-models of Amazonian forest and post-deforestation pasture (see www.criatividadecoletiva.net/cbm-files/212121b8cce515189041c26e685026cb61.DOC).
} 
to quantify with the present level of scientific understanding and data availability. The geographical distribution of carbon sinks is thus also not known with certainty.

As a result, country estimates of national carbon budgets are highly uncertain, with important consequences for international politics related to climate change. Under the Kyoto Protocol, Annex-1 countries can deduct carbon absorbed by national terrestrial biomes from their total estimates of national greenhouse gas emissions, provided the absorbed carbon is caused by human activities. The larger the size of a given country's estimated anthropogenic carbon sink, the easier and less expensive it is for a country to meet the emission reduction targets to which they have committed under international agreements such as the Kyoto Protocol.

Supported by studies which, at the time, located a significant amount of "carbon sinks" in North America due to new-growth forests and other types of young vegetation, US officials thus pushed hard to allow sinks to off-set estimates of total emissions under the Kyoto Protocol. The European Union opposed the US on this issue, seeing it as a loophole that would limit overall emission reductions and thus undermine the effectiveness of the Kyoto Protocol. ${ }^{9}$ A variant of the US position prevailed over that of the EU during the first commitment period of the Kyoto Protocol: nations were allowed to offset part of their national emissions reductions by carbon estimated to be absorbed by national, anthropogenic carbon sinks.

This new political economy of the global carbon budget politicized carbon-related science. The politics are heightened by the fact that scientists believe that they largely know the size of the missing sink while its location(s) are disputed, because this creates a zero-sum situation: the larger the alleged carbon sink in any given country, the smaller the total of all remaining carbon sinks outside its borders. Countries therefore tend to use uncertainties related to global carbon sinks and sources to produce the lowest possible estimates of their national emissions (Fogel 2002). In line with this, the USA has an interest in high estimates of its national carbon sinks, while those wanting the USA to reduce its fossil fuel emissions have an interest in finding carbon sinks outside the USA.

A particularly polemic scientific study was published by American scientists in Science in 1998. Using a controversial modeling technique, the study localized the majority of the missing sink in the Northern hemisphere, and on US soil in particular (Fan et al. 1998). The authors of the study suggested that North America removes at least as much carbon dioxide as it emits, and perhaps more than it emits, largely due to regrowth in formerly cleared areas. This yielded the conclusion that the USA is not a net emitter of carbon, bearing no responsibility for human-induced climate change despite its infamous status as the world's largest emitter of carbon dioxide from fossil fuel combustion and the highest per capita emissions. A Science journalist summed up the potential political gain to be had from the study, writing that North America 'may have drawn the winning ticket in the carbon sink sweepstakes' (Kaiser 1998). The study galvanized a coalition of US actors opposed to national emissions

\footnotetext{
${ }^{9}$ European nations also have an economic incentive for this position (Fearnside 2001): (1) As a whole, they do not have massive forests allowing them to benefit from carbon sink accounting and (2) if other nations successfully pressured the USA to reduce its actual emissions, this would likely result in higher energy prices in the USA and hence a reduction in overall US economic competitiveness on global markets. Having enforced high taxes on energy to reduce their own consumption, European nations suffer economic disadvantage when competing against nations such as the United States without similar taxes on energy consumption.
} 
reductions and to the Kyoto Protocol. Some even suggested that 'If we [the US] are absorbing more $\mathrm{CO}_{2}$ than we're producing... [other] countries should be paying us to burn [their] fossil fuels' (Hansen 1998).

Also interested in the political capital of the study were US global change science administrators who, at the time of the study's release, were eager to undercut a mounting attack on climate science from a new Republican majority in Congress. They wanted to disprove charges that environmental science consistently served a liberal political agenda at odds with national economic and political interests. ${ }^{10}$

Combined with the broader political context, the 1998 study also politicized the atmosphere among LBA scientists, provoking mutual suspicion, even as subsequent studies quickly and forcefully challenged the 1998 study. Scientists mobilized to improve understanding of the global carbon budget and find the missing sink, and the LBA was part of that effort.

The global distribution of carbon is also of financial interest to less developed countries seeking financial compensation from industrialized ('Annex 1') countries through the Kyoto Protocol's Clean Development Mechanism (CDM) and other carbon trading mechanisms. The CDM allows Annex-1 countries to compensate for their emissions by financing emission reduction activities in less-industrialized ('Annex 2') countries that do not have commitments under the Kyoto Protocol. The political relevance of national carbon sinks persists despite the US withdrawal from the Kyoto Protocol because carbon uptake also translates into financial currency through voluntary trading of emissions credits outside of the UNFCCC framework, the compliance market involving mainly private buyers (traders, utilities, etc.).

Some level of US interest in the science also persisted throughout President W. Bush's Administration, as many expected future presidents to return the USA to the Kyoto Protocol. ${ }^{11}$ The political relevance of national carbon sinks can be expected to increase under the Presidency of Barack Obama. His administration has already declared its intention to re-engage and participate actively in the UNFCCC negotiations, where the question of sinks is likely to be a key issue. In a larger economic context, the question of carbon trading becomes part of a more comprehensive strategy to cope with the economic crisis. Strategists look to carbon trading as a way for the US to revitalize its economy by means of 'green technology,' as it can provide an incentive and consolidate some of the desired structural changes in the economy (Román and Carson 2009).

\subsection{Findings}

Five years into the program, LBA scientists have identified negative consequences of deforestation at local, regional and global levels, underscoring the importance of

\footnotetext{
${ }^{10}$ I base the point about US science administrators on interview data collected in August 1998 in Washington D.C. among global change science administrators in national agencies. Policy uptake of climate science has strong partisan dimensions in the USA, with Republicans being, as a whole, more skeptical of the science supporting concern about human-induced climate change and inclined to perceive it as biased in favor of a liberal political agenda. See, among many others, Brown (1996), Dunlap et al. (2001), Gelbspan (1997), Lahsen (1999, 2005a), Mooney (2005).

${ }^{11}$ In late 2005, writers of Business Week described a meeting in which $80 \%$ of US business leaders present predicted that the USA would accept mandatory caps on greenhouse gas emissions once a new administration took over after President W. Bush (Fogel 2007).
} 
combating deforestation and associated biomass burning, which releases greenhouse gases into the atmosphere. The goal of identifying the role of the standing Amazon forest in the global carbon cycle has been more elusive and controversial. There is evidence that rates of absorption and release in the Amazon vary depending on time and location, hence the different findings around the Amazon (Ometto et al. 2005). Measurements of fluxes of energy, water, carbon, and trace gases were collected by means of a total of 17 towers dispersed throughout the Amazon, ${ }^{12}$ in addition to aircrafts and satellite imagery. ${ }^{13}$

Given the geopolitical interests in the science, it triggered suspicions when a certain division arose between American and European LBA scientists on the question of whether or not the 'undisturbed' Amazon is an overall carbon sink. The same division replicated itself among Brazilian scientists, reflecting whether they were working primarily with European or American scientists.

Empirical research performed by a team of Europeans and Brazilians in the Amazon, and published prior to the LBA, showed the relatively undisturbed forest site to be a large sink. Extrapolating from their 40 days of observation using a model, this group concluded that the forest area under study was a carbon sink on the order of about 1.5 tons/ha per year (Grace et al. 1995). Subsequent measurement by the same group, now compiling 1 year of data in another area of the Amazon, yielded a figure of larger than 6 tons/ha per year (Malhi et al. 1998). Later on, other studies in several Amazonian states under the LBA yielded figures of 2-6 tons/ha per year. The 6 ton figure is very large and at odds with long-standing, textbook ecological theory, according to which mature tropical forests are in carbon equilibrium, releasing as much carbon as they absorb through photosynthesis (Ometto et al. 2005).

Applying a new conceptual framework and extending results from a project that had collected air samples during 1 month in 1987, American LBA scientists continued to identify a substantial part of the Amazon as approximately carbon neutral (Chou et al. 2002) and pointed to biases in the measurements due to the 'eddy flux' technique using towers to study air fluxes above the tree tops. The measurement method used only works when there is turbulence in the air whereby the net carbon dioxide crossing from the atmosphere into the canopy (during daytime) or the other way around (during nighttime) is gauged by devices mounted at the top of the tall towers. Yet, during nights in the tropics, turbulence is low roughly $50 \%$ to $90 \%$ of the time. In the absence of turbulence, $\mathrm{CO}_{2}$ emissions may escape measurement, especially when combined with certain typographical factors, such as a gradual incline, which can lead $\mathrm{CO}_{2}$-rich air away from the towers along the ground before it eventually rises and mixes with the overlying air. As a result, the tower measurements might be missing a lot of the carbon being reemitted by the forest. In the daytime, forests are a carbon sink. During nights, they are a source, as they release carbon absorbed during the day through photosynthesis. Hence, if nighttime sources are

\footnotetext{
${ }^{12}$ There are now 12 standing towers. The towers were deliberately placed in areas characterized by different vegetation, soil chemistry, agricultural practices etc., to attempt to account for the ecological complexity of the Amazon.

${ }^{13}$ It is important to note that the LBA subsumed a wide variety of projects beyond those focused on carbon. For an example of a very different type of project, see Brown et al. (2002).
} 
under-measured, the whole forest sink may be overestimated (Fitzjarrald and Moore 1990; Saleska et al. 2003 ${ }^{14}$ ).

The Harvard-linked, American wing of LBA scientists and their Brazilian collaborators applied the $\mathrm{u}^{*}$ filter, a mathematical method of compensating for the nighttime measurement bias which was developed as part of studies of temperate forests in the USA in the early 1990s (Goulden et al. 1996). Applying this filter reduces the magnitude of the sink. Supporters of the filter recognize the limited physical understanding supporting this correction but argue that the filter nevertheless is necessary to compensate for errors in the data. ${ }^{15}$ European LBA scientists and their Brazilian allies are skeptical of the filter and refrain from using it. They claim that it introduces as much error for the typical Amazonian landscape as it corrects, and describe it as a systematic but problematic discarding of data unguided by understanding of the 'correct' quantities involved (Andreae et al. 2002; Araujo et al. 2002; Malhi et al. 1998).

Although American LBA scientists were skeptical of the large sink finding from the beginning, it prevailed in the Intergovernmental Panel on Climate Change's report on land use and land cover change (Intergovernmental Panel on Climate Change 2000). The report even boosted the status of the estimates by omitting accompanying caveats indicating limited reliability of the 6 ton/ha per year figure. ${ }^{16}$

Site choices appear to have been crucial to the divergent findings between American and European LBA scientists. American LBA scientists concentrated the large majority of their research at one particular site in the Amazon, namely Santarém in the Amazonian Tapajós forest in the state of Pára. American studies focused on that site identified a net carbon source (Miller et al. 2004; Saleska et al. 2003), yielding figures very similar to the Harvard group's 1987 aircraft results. These results, however, contrasted those derived at all the other LBA sites where Europeans concentrated their efforts; the latter were all found to be net carbon sinks (Araujo et al. 2002; Grace et al. 1995; Malhi et al. 1998; Malhi and Phillips 2004). Taking a broader, more pan-Amazonian approach, Europe created, and funded research at, a multiplicity of sites. With Brazilian assistance, Europe erected nine of the 12 research towers around the Amazon, thus covering more of the region and associated variability.

The correlation between LBA scientists' positions on this issue and their governments' respective interests and positions in international climate politics caused mutual suspicions of political influence. Brazilian, European and American scientists alike aired suspicions as to the objectivity and motives on the part of their counterparts in the LBA, perceiving national geopolitical interests to bias their positions on the sink issue. For instance, a Brazilian LBA participant identified geopolitics as the decisive cause in a 2002 interview as follows:

Most US scientists I've met come to Amazônia with a preconception that it is a large source of carbon. They, by and large, are attempting to disprove any

\footnotetext{
${ }^{14}$ See also on-line supplement to Saleska et al. (2003), accessible at: http://www.sciencemag.org/ cgi/content/full/302/5650/1554/DC1.

${ }^{15} \mathrm{My}$ primary source for the last two points are interviews with LBA scientists, backed up by scientific papers. See, for instance, Saleska et al. (2003), including on-line supplement.

${ }^{16}$ Yadvinder Malhi. Interviewed in Fortaleza, Brazil, 11 November 2003.
} 
positive effect that the forest may have as a sink. On the contrary, European scientists attempt to prove that it is a sink because that plays up for their position in the negotiations.... In sum, this is a politically charged issue and the idea of scientists as individuals seeking the truth above anything else is very far from the truth.

However, such suspicions have grown relatively few and muted more recently. New studies have narrowed the differences in estimates and LBA scientists gradually converged towards the understanding that the Amazon involves greater internal complexity than initially recognized. Some LBA scientists have also noted that suggestions of top-down political control of scientists is belied by the fact that the pattern of division does not extend beyond the LBA, which is a small sample size; some non-LBA American ecologists also posit the Amazon as a carbon sink (Nemani et al. 2003) and some European scientists are skeptical of evidence of a sink in the Amazon (Lorenzi 2005).

The US choice of Santarém fueled speculations among some European and Brazilian LBA scientists that it was chosen with prior knowledge of the results it would yield, since findings of carbon absorption in the Amazon undermined US political interests. Such suspicions remain unsubstantiated. By contrast, it is clear that cognitive and practical factors shaped Americans' choice to concentrate at one site, and why they chose Santarém in particular. (For analysis of practical and possible disciplinary factors underpinning American versus European site choices and differences in scientific interpretations, see online supplement \#3).

More recently, European LBA scientists have modified downward their earlier estimates in light of new findings. They agree that the estimates of carbon storage on the order of 6 tons/ha of Amazon forest per year were unrealistically high. Recognizing the weaknesses of tower measurements, LBA scientists as a whole now base their estimates also on forest inventories and so-called 'inverse' calculations of carbon sources and sinks (Baker et al. 2004). With their respective Brazilian collaborators, American and European LBA groups alike collected biometric data tracking the changes in living and dead biomass, which provided independent evidence that small sinks are the norm (Malhi and Phillips 2004; Saleska et al. 2003).

Recent studies have greatly narrowed the gap between the estimates since 2002. However, an informal survey by the author in 2006 suggested that American LBA scientists continue to place their bets at the lower end of the plausible range of sink estimates compared to their European counterparts. ${ }^{17}$ They are inclined to see the sink closer to zero and no more than 0.5 tons/ha per year, while Europeans and Brazilians interviewed tend to define the range as stretching from 0.5 to 1.0 tons/ha per year. This is in line with the published interpretations of the two groups (see Chambers et al. 2004 and Baker et al. 2004, respectively). While the difference between the two interpretive inclinations is relatively small per hectare, they are significant when the numbers are multiplied to cover the expansive size of the Amazon forest.

\footnotetext{
${ }^{17}$ The sample size is small, but so is the population of scientists in focus. Scientists surveyed were asked to define the size of the sink both objectively, in number per carbon per hectare per year, and by subjectively defining it as "small," "significant," "insignificant," or by use of terms of their own choosing. I also asked scientists to indicate their perceptions of the positions of other LBA scientists.
} 
It is at least possible that changes in political context also helped reduce the mutual suspicions. The narrowing of divergences among LBA scientists coincides with a reduction in the intensity of carbon cycle politics because of the US withdrawal from the Kyoto Protocol and more modest expectations as to the monetary gains to be had from carbon trading schemes. As 'science studies' have revealed, scientific evidence is subjected to greater scrutiny and deconstruction the more it bears on political and economic interests (Jasanoff 1990; Jasanoff et al. 1995; Dickson 1989; Lahsen 2005a, b). (For a general discussion of governmental influence on science, see Supplementary Information \#4).

Given the central involvement of NASA, it bears noting that top-down political influence can be exerted relatively more through mission-oriented federal agencies compared to universities. Such agencies are more conducive to the US government's long-standing practice of harnessing environmental research to national security interests, blurring common distinctions between civilian and classified realms of American government and science (Cloud 2001). That said, the author's investigations did not reveal evidence of top-down political pressure by NASA on LBA scientists to produce particular results. Despite many occasions to do so with impunity, no US or EU scientists interviewed shared experiences of such pressuring apart from the indirect and subtle means of funding structures. LBA scientists themselves are inclined to understand the narrowing of the gap between the different interpretations as a result of a well-functioning scientific process by which improved understanding and integration of various pieces of evidence related to the scientific problem eventually reduces uncertainty and controversy.

\section{Brazilian positions on the sink question concerning the Amazon}

\subsection{Brazilian scientists}

As a non-Annex 1 country, Brazil is not committed to emissions reductions during the first commitment period under the Kyoto Protocol, limiting political interest in national carbon sinks as far as its commitments under the Protocol are concerned. However, terms are being renegotiated for the second commitment period which begins in 2012, and there are strong pressures on Brazil to accept binding commitments to reduce emissions. Even if that does not happen, Brazil has important stakes in this issue. Brazilian actors look to the CDM as well as voluntary trading of emissions outside of the UNFCCC as a source of foreign capital by which to gain advantage at the levels of capital influx, development and environmental sustainability. Sinks are also potential currency in voluntary trading of emissions credits outside of the UNFCCC framework, the compliance market involving mainly private buyers (traders, utilities, etc.). ${ }^{18}$

Mere preservation of standing forests does not qualify for financial support through the CDM. The CDM allows Annex 1 countries to compensate non-Annex

\footnotetext{
${ }^{18}$ For more on greenhouse gas emission reduction schemes within and beyond the FCCC, see http://www.dti.gov.uk/ccpo/opportunities.htm.
} 
1 countries for avoided deforestation only in the case of deliberate human effort to (re)plant forests. Brazilian diplomats align themselves with Europe and other nations against inclusion of standing forest conservation on the list of fundable CDM activities. They point to technical difficulties of identifying forest preservation clearly resulting from human activities, and to the problem of 'leakage' (i.e., deforestation merely moves to another area), as well as dangers of creating counter-productive incentives and 'phantom' carbon credits which (in the words of a Brazilian official aligned with this view) allow the big, Annex 1 polluters an 'excuse to pay a little bit of money and keep their unsustainable energy consumption' and, as such, undermine the original intent of the Kyoto Protocol to reduce fossil fuel emissions (for the full statement of this government official's defense of this stance and a discussion of its merits, see Supplementary Information \#5).

Another subset of Brazilian actors-largely environmentalists and scientistspushed to include preservation of standing forests on the list of activities eligible for funding under the CDM. Framing deforestation as possibly decisive in global efforts to stabilize greenhouse gas concentrations at safe levels, Brazilian and American scientists affiliated with US and Brazilian activist think tanks and with INPE thus proposed the concept of 'compensated reduction' whereby countries electing to reduce national level deforestation below a previously determined historical level would be recompensed post facto and commit to stabilize or further reduce deforestation in the future (Santilli et al. 2003; Santilli 2005). Their idea was to create largescale incentives to reduce tropical deforestation, to broaden developing country participation in the Kyoto Protocol, and to leverage support for the continuity of the Protocol beyond the 2008-2012 first commitment period in face of mounting pressure on developing countries to assume emission reductions as well.

One of the authors of that proposal was LBA co-founder Carlos A. Nobre, scientist and former director of the Brazilian federal Center for Weather Forecasting and Climate Research (CPTEC) at INPE. He promoted his support of this strategy through the Brazilian media, e.g., a 2003 editorial in the widely circulated Brazilian newspaper, $O$ Estado de São Paulo, in which he estimated that Brazil's forests were providing ecosystem services worth somewhere between 1.5 and six billion dollars per year (Nobre 2003). His calculation was derived from two estimates: (1) an LBA-derived estimate according to which the Amazon forest is responsible for the absorption of at least $10 \%$ of the circa three billion of tons of carbon pulled from the atmosphere by terrestrial ecosystems and (2) an estimate of CDM carbon credits at five dollars per ton of carbon not emitted, based on 'pre-market' projections of the value of carbon credits for the first commitment period of the Kyoto Protocol. Nobre argued in support of the new economic paradigm that places actual economic value on these and similar ecosystem services, and presented avoided deforestation as the most efficient and desirable strategy for capturing carbon.

As I show below, Brazilian media were receptive to this framing.

\subsection{Brazilian media}

The Brazilian media has helped promote an interpretation of the Amazon as a large carbon sink as well as the notion that this can benefit the country. As I argue below, coverage of the pro-sink view in the Brazilian media has been significantly more extensive, both in number and length of articles. The pro-sink articles studied also 
tend to be more committed in tone than those describing findings that the Amazon may not be a sink. LBA scientists appear to have been an important factor in this, judging from how often they were cited in the media supporting this interpretation.

Brazilian media consistently favored the larger estimates of the Amazon as a carbon sink. One year into the 6 year LBA experiment, newspapers reported conclusions in favor of the pro-sink interpretation. For instance, an article about the LBA in $O$ Liberal suggested that LBA scientists 'already had concluded that the forest is absorbing atmospheric carbon dioxide and that part of these gases are emitted by industries, mostly industries in the northern hemisphere' (O Liberal 1999). During the period of most active fieldwork (2002-2005), the Brazilian medias' favoring of the pro-sink estimate was perceived and noted in the author's interviews and informal conversations with Portuguese-speaking American LBA scientists who follow Brazilian media and politics. It was also supported by my own monitoring, including a relatively more detailed study of articles in major Brazilian news-outlets limited to the year 2002. I identified the articles through two sources: (1) the archives of news clippings gathered within the Brazilian Ministry of Science and Technology to inform Brazilian decision makers on issues related to climate change ${ }^{19}$ and (2) a website dedicated to news clippings about the LBA. ${ }^{20}$ For the year of 2002, these two sources yielded a total of 12 articles discussing whether or not the Amazon is a carbon sink.

In the 12 articles that appeared in 2002 in the major Brazilian printed news media, eight were devoted to evidence in favor of the Amazon being a sink ("pro-sink articles"). ${ }^{21}$ While the power of this numerical evidence is limited due to the small sample size, content analysis reveals a strong and consistent pattern in favor of the pro-sink argument. Compared to the articles reporting countervailing evidence, the pro-sink articles were longer and more extensive in their discussions, making up a total of 80 paragraphs whereas articles reporting that the Amazon may not be a sink only totaled 25 paragraphs. In all but one case, the latter were brief notices about a new study which concluded that carbon escapes tower detection through leakage via rivers and other waterways, reducing earlier regional estimates of carbon absorption. Two of them consisted in single paragraph notices.

\footnotetext{
${ }^{19}$ Most centrally these decision makers were part of the Interministerial Commission on Global Change, which articulates governmental actions relative to the UNFCCC. The news clippings were from major Brazilian media outlets, including Gazeta Mercantil; O Estado de SP; O Globo; Valor Econômico; Scientific American Brasil; Folha Ciência; Corrêio Braziliense; Folha de São Paulo and Jornal do Brasil.

${ }^{20} \mathrm{http}: / /$ www-eosdis.ornl.gov/lba_cptec/lba/port/documentos/materias/20020219.html

${ }^{21}$ One of these articles was equivocal. It stated that "By contrast to results from earlier experiments, [a new LBA study shows that the Amazon] pulls roughly the same amount of carbon dioxide from the atmosphere as it emits." However, it also described the study as indicating that each hector of the Amazon forest absorbs 2 tons of carbon more than it emits, and quoted the researchers' own evaluation of this amount as "significant, despite being smaller than originally thought." Moreover, it was the 2 tons carbon absorption capacity that captured the headline (Escobar 2002). I thus count this article in the pro-sink category. In an e-mailed response to my request for clarification, the cited scientist described his view as being that the (limited) evidence suggests that the Amazon is a small sink (0.5-1.0 tons per hectare per year, by contrast to earlier estimates of 2-8 tons), but noted that this is a "significant" number and one that offsets the emissions by biomass burning.
} 
Coverage of the pro-sink findings was also more committed in tone, with assertions such as the following:

Investigations under the LBA and parallel work ... confirm that, contrary to what was previously thought, when the forest was understood as being in overall equilibrium as far as carbon was concerned, it (the forest) is an enormous carbon sink. The numbers vary according to methodology and the region investigated, but it is generally accepted in the Amazon that the forest absorbs between one and nine tons of gas per hectare per year (Capozzoli 2002);

From the point of view of researchers, one of the most significant contributions of the LBA is its overcoming of the thesis that the forest is in equilibrium or a source of carbon (Capozzoli 2002);

The Amazon is considered a large global reserve of carbon. Scientific studies carried out under the LBA... have already proven that the forests function as true carbon sinks, absorbing between 0.8 and 1.5 tons of $\mathrm{CO}_{2}$ per hectare (Silveira 2002b)

The thesis that the Amazon forest is a large emitter of carbon is outdated. Researchers [at the second biennial LBA conference in Manaus in July 2002] revealed that the forest is a carbon sink, contributing to the reduction of global warming (Jornal do Brasil 2002)

Already completed field research under the LBA ... reinforces the thesis that the Amazon forest contributes to the reduction of the greenhouse effect, absorbing more carbon than it releases (Silveira 2002a)

[T] he Amazon forest absorbs a total of 0.4 to 1.0 gigatons of carbon per year from the atmosphere. That value is equivalent to the annual emission of $\mathrm{CO}_{2}$ from fossil fuels in Western Europe (0.9 gigatons of carbon in 1996) and 5-12 times more than the emissions of carbon from fossil fuel combustion in Brazil (Silveira 2002a)

Despite fires, the Amazon forest manages to filter an immense quantity of carbon: up to 500 million tons. 'This is an important input for public policy. Because while we know little about the Amazon forest, we do know that it is-and very much so-contributing to the reduction of the impact of global warming,' said the president of the LBA's scientific committee, Carlos Nobre (Rede Globo 2002)

By contrast, coverage of countervailing interpretations of the Amazon as more or less carbon neutral was generally uncommitted in tone. Roughly half of these articles emphasized the potentially negative policy consequences of such conclusions, noting that evidence in favor of the forests being sinks can strengthen forest preservation. One article suggested that the finding justified more research. None identified positive policy consequences of the no-sink scenario for Brazil.

Interpretations of the Amazon as a sink and, as such, beneficial to Brazilian national interests pre-date the LBA. At the height of a wave of especially intense international concern about the destruction of the Amazon forest in the late 1980s and 1990s, Brazilian scientists similarly stressed the environmental services the 
Amazon provides. Evoking framings of the forest as the 'lungs of the world,' some called for greater forest preservation and for the world's major polluters to financially recompense Brazil for the air the Amazon was believed to cleanse (Benvenuti 1990), thus pressuring both Brazilian and foreign governments.

The first Brazilian scientist to bring flux tower technology to Brazil, Luíz Carlos Molion, widely disseminated this understanding in the late 1980s and early 1990s. Molion told national newspapers that the Amazon controls global warming by absorbing the pollution emitted globally (Adeodaio 1990), and that the finding indicated 'one more reason to preserve the forest' (Caropreso 1990) and could translate into national gain through international deal-making around carbon (Adeodaio 1990). ${ }^{22}$ Molion stressed that Brazilian forests appear to absorb carbon ('pollution') emitted by other countries, including those who are the most critical of Brazil because of its high national deforestation rates. At the time, Brazil was suffering especially intense international pressure because of deforestation rates in the Amazon and the environmental impact of fires. The data about the Amazon's carbon sequestration capacity could lessen the foreign pressures on Brazil, Molion wrote, explicitly noting that it could help Brazilian diplomats position Brazil more favorably in international environmental negotiations (ibid.). Interestingly, Molion based his conclusions on the above-mentioned 1987 Harvard study, which identified a substantial part of the Amazon as approximately carbon neutral and the authors of which did not agree with Molion's conclusions.

The same framing continued to prevail in 2006, despite downward modified estimates of the carbon absorption. For instance, the title of an article in January 2006 in a Manaus-based newspaper read: "Brazil can earn from carbon sequestration." In it the Brazilian forest ecologist and former LBA participant, Niro Higushi, describes the Amazon's carbon absorption capacity as a 'principal weapon by which to pull carbon from the atmosphere ... and, that way, benefit [Brazil and the Amazon region] financially by selling carbon credits to the world's larger polluters' (Menezes 2006). Greatly amplifying the effect of this and other such coverage, the environmental NGO named Brazilian Friends of the Earth circulated it through its international, electronic mass-mailed news clipping service (www.amazonia.com.br), which also translates highlights into English.

By contrast, neither my interviews nor media analysis revealed any Brazilian scientist—or journalist, for that matter-who stressed the no-sink argument and tied it to a positive definition of national interests. Interestingly, and in line with the above example of Molion, even Brazilian scientists who work primarily with American LBA scientists under the LBA were inclined to advance the pro-sink argument, an example being Niro Higushi, the Brazilian Amazon-based former LBA forest ecologist cited immediately above.

\subsection{Brazilian decision makers}

Everything else being equal, one might expect Brazilian decision makers in charge of climate policy to be receptive to the interpretation of the Amazon as a sink.

\footnotetext{
${ }^{22}$ The main basis for his claims was a study by the Harvard-led group of American LBA scientists (Fan et al. 1990) which found a sink on the order of 2.2 tons of carbon per hectare per year, albeit on the basis of very limited data covering only a period of 8 days.
} 
As we have seen, the latter (1) prevailed in the IPCC; (2) was supported by respected national scientists, including the director, at the time, of the federal laboratory responsible for climate research in Brazil; (3) dominated in the Brazilian media; and (4) was widely presented as being in the national interest for both financial and environmental reasons. Despite this, key Brazilian policymakers and diplomats remained unconvinced by the argument that the Amazon is a carbon sink, including the associated suggestion that such findings would serve Brazilian interests by strengthening Brazil's position in international climate negotiations and attracting foreign funds for forest protection.

Central decision makers I interviewed in the federal government recognized the dominance of the pro-sink argument among LBA-involved national scientists and in the national media, but they were skeptical of it. The two governmental entities most centrally responsible for shaping Brazil's official position on climate change under the UNFCCC are the Brazilian ministries of foreign relations (also called the Itamaraty) and science and technology (henceforth referred to as the MS\&T). In interviews with me, diplomats from the Itamaraty expressed skepticism with regards to the pro-sink argument about the Amazon and pointed to uncertainties in the scientific knowledge. A policy maker from the MS\&T characterized the view of the Amazon forest as a sink as 'a bias on the part of the researchers.' Another policy maker from the same ministry shared that perception and referred to the evidence of a carbon sink in the Amazon as 'junk science.' When asked why, he answered: 'Because they have [so few] towers in the Amazon and they are using eddy correlation to measure the flux.' 23 He subsequently offered a technical discussion to support his view, highlighting the problem of night time turbulence and of extrapolating to the Amazon forest as a whole from studies focused on so few and tiny forest areas:

They are measuring that the Amazon is a sink-according to [mentions a prominent national scientist by name] on the order of from 0.5 to 2 tons of carbon per hectare. They have only [a small number of] towers in the whole Amazon. And they multiply this by the total area of the Amazon region. And they have measures during 2000 and 2001—which means, during La Niña. So we can't know for sure that the same will happen during El Niño. So, lots of uncertainties. And then they say that Amazônia is a sink. It is too much. I don't know anything about forests. But it is not reasonable for me what he is saying!

\section{Analysis}

4.1 Political and institutional aspects bearing on environmental decision making in Brazil

What might explain these decision makers' skepticism with regards to the prosink evidence and arguments? Were they more convinced by American scientists' authority on the issue? While that cannot be ruled out, it is unlikely. For one, American researchers' conclusion of approximate carbon neutrality were drawn

23 "Eddy correlation" is a less used term for "eddy covariance". 
from similarly spotty, uncertain evidence based on the same measurement techniques that the policymakers dismissed as inconclusive-indeed, the evidence of the standing forest as a source came from the single research site in Santarém, Pará. Moreover, Brazilian policy makers generally recognize Brazilian climate experts, including Carlos Nobre, as top notch scientists on a par with the best of their peers in North America and Europe, as do the foreign scientists who know them. ${ }^{24}$ Indeed, Brazilian policymakers tend to rely more rather than less on national scientists, as evidenced in their emphasis on Brazilian participation in international science assessments such as the Intergovernmental Panel on Climate Change (Lahsen 2004).

In conversations with me, the policy makers in question did not invoke alternative peer-reviewed science to justify their resistance to the pro-sink science interpretation. Mirroring the tendency in national news coverage described above, they did not even note the schism within the LBA around the carbon sink issue in interviews with me. This can also be witnessed in the above quotes in which policymakers present LBA scientists as a non-differentiated 'they:' 'that bias comes from the researchers,' 'They have only five towers in the whole Amazon,' etc. The first American nosink findings based on LBA research were published only half a year prior to these interviews, perhaps contributing to the lack of recognition of the divergent interpretations within the LBA.

The most plausible explanation for these Brazilian policymakers' attitudes to sinkrelated science is arguably found in cultural, political and historical factors, including attitudes reflecting institutional cultures and structures of which the decision makers are a part. As I argue below, their skepticism harmonizes with subtle but persistent features of national political culture, ${ }^{25}$ including understandings related to the Amazon and Brazilian interests in international politics, as well as long-standing tendencies in Brazilian environmental policymaking, in particular an emphasis on developmental goals, bureaucratic fragmentation, and a tendency towards 'corporatist' (i.e., non-transparent, non-participatory) decision-making. ${ }^{26}$

The government officially explained the decision against inclusion of standing forests under the CDM in terms of legitimate technical difficulties of verifying and quantifying sequestration activities and of avoiding counter-productive incentives and so-called 'leakage' (i.e., deforestation merely moves to another area). However, at least the problem of leakage also applies to reforestation and afforestation activities that the Brazilian government chose to support as fundable under the CDM. Additional, less explicit concerns arguably shaped the government's opposition to including preservation of standing forests under the CDM. Importantly, the pro-sink

\footnotetext{
${ }^{24}$ The scientific credentials of LBA scientists were noted by many European and American scientists whom I interviewed.

${ }^{25}$ Following Wiarda (1990: 32), my use of the term "political culture" refers to "the basic values, ideas, beliefs, preferred institutional arrangements, and practices by which a society organizes its political life."

${ }^{26}$ Checkel (1997) uses the term 'corporatism' to describe what Friedman and Hochstetler (2002) also capture with the term 'cooptive democracy.' The two terms are near equivalents and refer to systems marked by a hierarchical state-society relationship in which decision makers enjoy greater power to dictate national policy as they wish, compared to liberal systems, in which decision makers' power is more restrained by democratic controls and 'bottom-up' pressures. On the other hand, corporatist systems do integrate considerable input from society, by contrast to 'statist' systems. In the latter, the state is 'above' society and much more insulated from bottom-up input.
} 
argument conflicted with Brazilian diplomats' strategy to minimize discussion of deforestation in international climate negotiations because it is Brazil's 'Achilles heel' in this issue area. With $46 \%$ of its total energy consumption derived from renewable sources against the world average of $12 \%$, Brazil has an exceptionally "clean" energy matrix (MME 2007), even considering the possibility that greenhouse gas emissions from its hydroelectric dams and associated downstream rivers may be higher than previously estimated (Fearnside 2006; Guérin et al. 2006, 2008). Deforestation causes roughly half of Brazil's greenhouse gas emissions. This instigates international pressures on the government for change, which in turn raises national sovereignty concerns and conflicts with national political and economic interests.

Despite countervailing trends, Brazil has a long, continued tradition of viewing the Amazon as a means of reaching national development and geopolitical goals, for which reason its political leaders also attempt to maintain national control over it (Becker 2001; Barbosa 1993; Guimarães 1991, 2002; Hurrell 1992; Martins Filho and Zirker 2000; Schmink and Wood 1992; Wood and Schmink 1993). ${ }^{27}$ Brazilian environmental conservation laws are strong but weakly enforced, a function of lack of resources, political will, and effective institutions (Guimarães 1991, 2002; Hecht and Cockburn 1989; Vianna Rodrigues 2004; Wood and Schmink 1993). Economic interests responsible for deforestation in the Amazon hold great power in Congress (Tabak 2005) and the government's ability to control activities within the vast territory is limited: some $80 \%$ of the deforestation is illegal (Vianna Rodrigues 2004).

The Ministry of Foreign Relations' control of Brazil's official position on climate change in international negotiations is partly a function of national security sensitivities regarding the Amazon region, and because the deforestation issue first appeared within the Brazilian political purview when foreign governments expressed concern about it in international forums. This forced the Itamaraty to produce an official, national position on deforestation and climate change, in conjunction with the President of the Republic and the military (Jakobsen 2000). Then, as now, environmental policy reflects the dominance of these institutions and their inclination to subsume environmental issues to development and natural security interests, defined militarily (Guimarães 1991, 2002).

Some officials within the environment ministry supported the pro-sink argument and shared the associated perception of national advantage in the form of forest conservation through carbon trading mechanisms. However, while environmental protection is its institutional mission, this ministry is weak and marginal in the international negotiations compared to the Itamaraty and the MS\&T; it ranks relatively lower within the governmental hierarchy compared to the latter.

The environment ministry's weakness in the climate arena was both reflected and reinforced by its late involvement with climate politics, and it continues to be compounded by the fact that the ministry has fewer financial resources and less technical expertise on the issue of climate compared to the MS\&T. The MS\&T is controlled by the Itamaraty, which it assists on technical issues. Until around 2001, the environment ministry, like most other parts of the government, had little

\footnotetext{
${ }^{27}$ The precedent of this goes back further: Since the 1500 s when Brazil served as a colony for exploitation by the Portuguese, Brazil has been interdependent with external economic trends and tended to view nature as a source of raw materials and development but also as an obstacle (Barbosa 1993).
} 
interest in climate change. With one or two exceptions, Brazilian NGOs were similarly immobilized on this issue. ${ }^{28}$ This began to change around 2001 . Influenced by a similarly changing NGO community and newly aware of the weakness of the Convention on Biological Diversity on which it thus far had concentrated its efforts at forest conservation, the ministry began to seek involvement in climate policy processes, seeing the climate convention as a potential means of improving forest protection.

As architect of the National Climate Plan as well as new, more aggressive policies and strategies to decrease deforestation, especially under Minister Carlos Minc who took office in 2008, the Brazilian Environment Ministry is in the process of assuming a new level of control of domestic climate-related policy. The Ministry has also taken steps to remedy its technical weakness in the area, in part by creating a new Climate Change Secretary post within the Ministry, to which it appoints credentialed scientists. Launched in December 2008, the National Climate Plan is the first national policy to reduce human-induced climate change and its impacts independent of international negotiations. Due to the newness of these developments, it has yet to be seen how well the Environment Ministry will be able to exercise control over climate affairs in practice. ${ }^{29}$

The fact that the environment ministry long has supported the inclusion of standing forests under the CDM underscores the importance of political agendas and institutional commitments in the selection of interpretations related to the Amazon's role in the global carbon cycle. It also reflects differences in how different branches of the Brazilian government relates to civil society. Compared to the Itamaraty and the MS\&T, the environment ministry maintains a closer relationship to Brazilian environmental groups and scientists. In 2008, four of the ministry's five top leaders were themselves from environmental non-governmental organizations. Reflecting this ministry's affinity with the pro-sink argument, and by contrast to the Itamaraty and the Itamaraty-controlled MS\&T, it invited Carlos Nobre to be part of the Brazilian delegation in the international climate negotiations, the above-mentioned CPTEC director and LBA architect. In 2008, it also invited him to serve as its Secretary of Climate Change when the position was created.

By comparison, the decision makers from the other two ministries are relatively more circumspect in their inclusion and reliance on national environmental scientists. As one of them relayed to me: especially when it comes to deforestation in the Amazon, both foreign and Brazilian scientists are 'normally very biased in terms of policy; they use [science] to blame Brazil for misusing the Amazon forest.' On this issue, he noted, Brazilian environmental scientists are 'not contributing to our [i.e. the government's] strategy,' referring to the strategy of minimizing discussion of national conservation policies and to not support the inclusion of forests under the CDM.

\footnotetext{
${ }^{28}$ I observed this first-hand during an initial round of fieldwork in Brazil in April 1999. At that time, the environment ministry and environmental NGOs were focused primarily on the Biodiversity Treaty and local environmental issues, respectively.

${ }^{29}$ Representing a reach of the Itamaraty inside the Ministry of Environment, its first Secretary on Climate Change (2007-2008) had close ties to the Itamaraty and the Ministry of Science and Technology who expressed. This Secretary was replaced when Carlos Minc assumed the minister post in 2008 and was part of the Ministry of Environment's agenda to assume greater control of the national climate agenda.
} 
Several of these policymakers responsible for forging Brazil's official stance against the inclusion of standing forests under the CDM commented that scientists interpret scientific evidence partly with view to pressuring the government on the forest issue. In the words of one of them:

[LBA scientists] are saying that the Amazon is a sink, and if you think the Amazon is a sink and you are deforesting the Amazon, then you have a bigger problem. So you are going to be accused that you are destroying the sink. So it is very complicated. And the result of it is to create a big effect to try to raise funds for their research from NASA, the USA and so on, and also [obtain funds] nationally, because you create a problem for the government by [implying that it] is destroying a sink, the 'lungs of the world'! This kind of thing. This is the problem: they use climate change to fit their political intents, their political agenda [.... So [they] start to mix things. And then ... use science to justify what [they] are trying to do. I don't like this!

\subsection{General features of environmental decision-making in Brazil}

Aside from the above-mentioned national security concerns and development interests, the pro-sink argument was up against yet other tendencies in Brazilian political culture and structures, including administrational legacies and long-standing and deeply institutionalized approaches to decision-making which challenge environmental policy throughout Latin America (MacDonald et al. 1997). As reflected in the above discussion, key obstacles include the subsumption of environmental administration within government bodies not primarily oriented towards environmental preservation, as well as bureaucratic fragmentation and formal limitations on participation in decision making. While these features are not exclusive to Brazil nor to Latin America as a whole, they are especially pronounced in this region (Mumme and Korzetz 1997).

In Brazil, as in Latin America in general, political leaders tied to national security often integrate an anti-political self-understanding, in line with a top-down, non-participatory approach to decision making. This non-democratic or corporatist approach to decision-making is linked to the belief that high-ranked decision makers can be trusted to single-handedly define national policy, and that they serve the common good better than the processes of democratic politics, which are equated with partiality (Fitch 1998; Sloan 1984).

Characterizing Brazil's political culture during the military dictatorship, Sloan wrote that it is part of the political culture of Latin America to fear interest groups operating independently of government and to generally act independently of any expressed opinions of the people (Sloan 1984). While there has been a huge democratic surge in Latin America since them, contemporary analysts continue to conclude that Latin American governments, as a whole, have yet to prove that they are willing to accept actors from civil society as partners at home and abroad (Friedman et al. 2001), and that authoritarian tendencies persist beneath democratic appearances (Hurrell 2005), as reflected, for instance, in state actors' continued heavy control, also over civil society's access to government (Friedman and Hochstetler 2002).

Democratic and authoritarianism tendencies coexist, however (Wiarda and Kline 2000) and expressions of the latter may assume more subtle forms as the democratic 
trend spreads in larger parts of government and society. One such subtle expression can arguably be read into an Itamaraty diplomat's words when he, in an interview, said that the ministry does call in NGOs from time to time 'to explain the government's decisions.' While it could be an oversight, he did not mention the need for the government to similarly learn from NGOs in this process, and the diplomats were the ones who decided and defined the place, timing and nature of the interaction. For their part, NGO representatives and a division secretary within the environment ministry at the time expressed that their meetings and general interactions with the Itamaraty failed to result in integration of their views and requests with regards to forest-related policy. ${ }^{30}$

Also suggestive of corporatism, and, in particular, of the core decision makers' distance from national interest groups, an interviewed official expressed deep discomfort at the rumor circulating near the beginning of the Lula government that the new administration might move climate affairs under the control of the environment ministry. He expressed low respect and even dislike for the environment ministry, differentiating it from the parts of the government with which he identified and which he referred to as 'the government.' He said that officials in the environment ministry 'don't work for government but are one with the NGOs,' referring specifically to non-governmental, environmental activist organizations. 'Their only concern is the environment,' he complained; 'they don't feel any responsibility beyond that level. Their only concern is the environment, so they are one with the NGOs. They come from the NGOs, so they represent that constituency, those perspectives, and are against the government.' Rather than legitimate actors that should be part of a democratic process of influencing and developing policy, he thus posited NGOs and, even, the environment ministry as opposed to the government, the latter apparently conceptualized as the small group within it's core with which he identifies and which he believes best able to define the overall national interest. In conversation with me, two freshly-minted Brazilian diplomats working in the environmental area in the Itamaraty similarly portrayed representatives in the environment ministry as lower status and less serious about their responsibilities, describing this as a reflection of the fact that they are civil servants and not submitted to the same rigorous screening exams and preparatory training as diplomats undergo before entering official posts in the Itamaraty.

In interviews, policymakers in the ministries of foreign relations and science and technology expressed critical distance from the expressed opinions of national scientists on the grounds of financial motives (i.e., the distorting effects of scientists' need for research funds) and limited political insight. As a scientist and political appointee within the Ministry of Science and Technology administration put it:

When you are strictly a scientist, it is difficult for you to perceive the implications of the results of your research, the political impact. We in government have better sense of that.

[Brazilian scientists pushing the idea that the Amazon is a sink] don't know the pressure we in government have about deforestation issues and when we go out to negotiate climate change, where forests are still a very, very

${ }^{30}$ This data is from 2002 , specifically. 
complex issue. Anything like that, saying it is a sink, promotes a commotion among negotiators that might guide the way things are going to be decided in the negotiations. It might impact how the negotiations might move. As a government, we didn't want conservation of forests to be an eligible project under CDM. As a government. But all the scientists are saying 'this is really good.' So there is a clash. Because these people do not understand deeply. Scientists think they get money for the region and research if they say that. But they don't see the larger context, the complex negotiations [that are going on between countries].

The decision makers' representations (e.g., 'this is really good' and 'they think they get money for the region and research if they say that') thus suggests that scientists' financial and political interests bias their portrayal of the science, and that their political views reflect their limited understanding of the full range of political games and considerations involved.

These same decision makers succeeded in excluding civil society from important government forums, in particular the Interministerial Commission on Climate Change (created in 1999), an intra-governmental body overseeing UNFCCC related affairs such as the CDM.

The point here is not that the Brazilian core decision makers would or should have accepted the pro-sink argument. Rather, it is that their rejection of the argument, including the discourses with which these rejections were communicated in interviews, reveals a relative distance between them, on the one hand, and, on the other, national scientists and activists advancing the pro-sink argument and pressing for greater forest protection under the Kyoto Protocol and beyond. The second point is that this distance bears marks of long-standing tendencies in Brazil's political culture. In what follows, I argue that these tendencies appear to be justified and thus perpetuated by means of a discourse portraying even national science and scientists as overly swayed by Northern, hegemonic interpretive frames and interests.

\subsection{Northern dominance of science}

My interviews suggested that "Northern" (i.e., the Northern hemisphere's and, more precisely, developed countries') dominance in science legitimated and reinforced tendencies towards insular decision making and critical distance to national scientists on the part of decision makers from the Itamaraty and MS\&T. Numerous decision makers from these ministries described dominant understandings of the global environment and associated framings of responsibility and policy options as infused with understandings and interests of the more powerful developed countries, most notably the USA. Moreover, such decision makers suggested that the combined effects of national scientists' foreign educations and their transnational socio-professional networks, their not uncommon affiliations with NGOs, and their interests in foreign research funds, compromised their ability to perceive and act in accordance with national interests. In a particularly clear articulation of this understanding, a central decision maker suggested that Brazilian scientists' foreign educations reduce their critical awareness and their ability to understand and serve national interests:

If you don't have a kind of domestic way of thinking, that reflects in your thinking of [the environment and related policy issues]; you are like a parrot, 
you are repeating what people are teaching you. And even in universities, you see this; people repeat what they hear in the literature. And that [literature] is from the developed countries.

Brazilian scientists I interviewed confirmed the existence of these perceptions on the part of national decision makers, albeit in an overall more subtle form than earlier decades, when members of the Brazilian military would attack scientists for adhering to the 'internationalist view' of deforestation as a problem and even accuse them of working as agents for the USA and international organizations. While said to be voiced especially 'behind closed doors,' scientists reported having heard people from the federal government expressing these 'demeaning' perceptions of foreigneducated national scientists, and at times also doing so 'straight to their faces.' One conservation-conscious scientist commented that national decision makers 'do not respect what Brazilian scientists are doing for the development of the country,' signaling his political differences with the Itamaraty in the area of defining national sovereignty and concerns: 'It is simply because we have a different view than this [national sovereignty-focused] Itamaraty view—-then you are attacked.'

\subsection{Complexity, ambivalence, and change}

The act of describing the political culture and its manifestations among decision makers can tend to reify and exaggerate dynamics that often are subtle and marked by complexity and ambivalence. While the scientist and policy maker cited immediately above express differences, they also frequently collaborate and interact, both in and out of the government, and share a general concern about the problem of climate change (Lahsen 2004). Their differences appear mostly at the level of how best to balance national development and sovereignty concerns with environmental concerns related to deforestation and climate change (ibid.).

The environment ministry most clearly represents a relative break with the non-participative, top-down tradition of policy making, which especially reigns in governmental arenas related to national defense and foreign diplomacy. However, in response to pressures from civil society in the last decade, there appears to be a gradual opening up of the government as a whole when it comes to outside input, including scientific input. There are indications of a gradual modification (even within the strongly institutionalized Itamaraty) in the form of occasional intrainstitutional exceptions to the Itamaraty's traditionally formalistic and hierarchical style. $^{31}$

\footnotetext{
${ }^{31} \mathrm{~A}$ particular Brazilian diplomat was portrayed by informants as an example of this younger generation displaying more openness and a somewhat less formal style of interaction and expression compared to what has been, and continues to be, the norm for Brazilian diplomats. Some suggested that his presence intimated a modification of the rigid and secretive style of communication to the extent of almost transforming the spirit of the Brazilian delegation at recent Conference of the Parties (COP) meetings under the UNFCCC. Other diplomats, including one that came to a 2004 meeting of the LBA's Scientific Steering Committee, appear to also break somewhat from tradition by manifesting a relatively more open and less formal and hierarchical attitude.
} 
The author also encountered shifts and ambivalence on the part of central decision makers, including one whom many interviewees identified as especially suspicious of NGOs and inclined to maintain government control over deforestation-related information. No longer in the government, this person expressed support for greater civil society participation in decision making in a 2005 interview, and described the actual tendencies towards insular, non-participatory decision making as 'unconstitutional.' In conformance with Roberto Guimarães' model (2002) and indicative of the institutional roots of the above-mentioned tendencies, his switch in institutional affiliation thus also shifted his expressed views; Guimarães (2002: 240) has observed that the position of bureaucrats in the Brazilian government expresses the culture of the agency they represent, which in turn reflects the institutional history of the agency as well as an associated assemblage of beliefs, values, symbols, professional leanings and crystallized patterns of behavior.

Explicitly in doubt as to the legitimacy and representativeness of his own views, another top climate decision maker urged that I also talk to various other actors both in and out of government before forming my interpretation of Brazilian climate affairs, and did so in the same conversation in which he had spoken disparingly about the MMA and environmental groups as unable to define national interests in a sufficiently impartial and inclusive manner.

While analysis of the triggers of these changes are beyond the scope of the present article, relevant factors appear to have less to do with changes in administration from Cardoso to Lula than with a more general-albeit timid and circumscribedopening of the government to civil society through societal pressure on elites and elite learning, in line with Checkel's model for norm diffusion in societies marked by corporatist tendencies (Checkel 1997). As an example, core decision makers were initially against the notion of the CDM altogether but were convinced otherwise by a few prominent actors representing academia, state government and civil society. Shifts in administrations also bear relatively less in this respect because Itamaraty diplomats' appointments transcend them.

Civil society has mobilized strongly around the issue of climate change since around 2001, and decision makers have engaged in increasing interaction with NGOs, industry and scientists around the issue, partly through the Brazilian Forum for Climate Change (BFCC). The BFCC was created in 2000 to channel civil society views into government and to compensate for the fact that civil society had been excluded from the Interministerial Commission on Climate Change, a function of the explicit wishes of powerful decision makers linked to the Itamaraty and the Ministry of Science and Technology. What led to the BFCC, and thus in this instance helped bypass intra-governmental resistance to civil society participation, were personal connections and conversations between then President F.H. Cardoso and Fabio Feldmann, a former elected politician aligned with Cardoso's political party and with the Brazilian environmental community.

\section{Conclusion}

Although the international scientific community disagrees on the question of whether or not - and to what extent — the Amazon is an overall carbon sink, Brazilian 
LBA scientists, environmental NGOs and the environment ministry, have sought to make evidence of a sink serve forest conservation. Brazilian scientists' efforts did little to overcome biases in the selection and framing of deforestation-related issues in Brazilian environmental policy; uptake of the pro-sink argument in government correlated with pre-existing institutional commitments related to forest preservation. Thus, policymakers against the policy of having standing forests be eligible for CDM funding discounted the pro-sink argument, while policymakers in favor of inclusion of standing forests embraced the notion that the Amazon might be a sink.

Analysts identify science as a 'powerful and persistent' prime force transforming international affairs (Skolnikoff 1993) and perceive intersubjectivity-i.e., shared meaning and beliefs about causal relationships - to characterize vast, transnational networks of scientists and policy makers interacting in scientific and diplomatic circuits around global or transboundary environment problems (Adler and Haas 1992; Haas 1989, 1990, 1992). However, it is important to also recognize and understand the limits of science and of its ability to engender change in political affairs, even at the national level and even when the issue also is marked by geopolitical divisions among decision makers and scientists in international arenas.

Factors shaping the influence of scientific knowledge and scientists on policy are understudied; precious little attention has been given to whether or not intended audiences of this information are receptive to the information being produced. At the practical level, this case study focused on Brazil suggests that policy advances in the area of global environmental problems at times depend less on additional scientific research than on enhanced understanding of internal struggles and other cultural and political particularities bearing on policy formation in countries and regions with leverage in global environmental politics. When science is not perceived as convenient, relevant, trustworthy, authoritative and neutral, more science may not be an effective solution.

This study also suggests that a deep-rooted political culture of decision making in Brazil circumscribes the receptivity of core decision makers to the opinions of the rest of the government and of Brazilian civil society, including scientists, and that those perpetuating traditional tendencies towards insular decision making in Brazil justify this by reference to Northern dominance in science, and on the basis of a construction of science as a means of hegemonic control through the shaping of subjectivities and environmental understanding.

Pressing further yet, the case study yields a number of observations and questions related to the role of culture and science in environmental decision making in Brazil, some aspects of which are likely to apply to other less developed countries as well, especially those with similar authoritarian traditions of decision making. It is notable, for instance, that Brazilian decision makers did not rely on alternative experts and evidence to justify their skepticism of the pro-sink argument, at least not in their conversations with me. This may be because there were no obvious alternative, domestic scientific authorities to cite, and because the incentive to change this lack was not sufficiently strong. Another important factor is that the science was not the explicit focus in international climate negotiations and related forums, nor in national arenas, where decision making tends towards non-transparency. This allowed the decision makers to express their views in the relatively relaxed atmosphere of an interview without being held to an official stance nor asked to present a formal exposition of supporting scientific knowledge. It also supports 
findings of a relatively weak coupling between science and decision making in Brazil (Jakobsen 2000).

I have argued that the influential Brazilian decision makers' lack of receptivity to the pro-sink argument is partly a function of institutional commitment to a preset, political agenda reflecting strong, long-standing tendencies in Brazilian environmental policymaking, including the dominance of developmental goals, bureaucratic fragmentation, and non-transparent, non-participatory decision-making structures. This confirms the well-established observation that actors tend to use the interpretive flexibility of science concerning uncertain environmental threats to serve their preselected political agendas. Only science seen as supporting predetermined political agendas is likely to escape deconstruction or dismissal. ${ }^{32}$

Had Brazilian national interests around the science been more acutely at stake, one might have expected relatively greater testing and contestation of the evidence involved within Brazil. Without commitments under the Kyoto Protocol and with important financial gains to be had through the CDM, there is little national-level political interest in deconstructing climate science, and Brazil has not seen the development of a vocal community of climate skeptics of the type seen elsewhere, especially in the USA (Goldemberg 1994; Lahsen 1999, b).

Further studies might probe connections between authoritarian (or specifically corporatist) political structures and national scientists' inclinations to engage in politics. ${ }^{33}$ Integrating contextual and theoretical knowledge related to the science-policy interface, such studies can be a valuable resource for efforts to identify and overcome obstacles in the information exchange between science and decision makers, with view to improving environmental decision making. Attempts at authoritarian control over civil society actors, including scientists, might galvanize rather than reduce scientists' overall inclination to do politics with science. As witnessed above, internationally respected Brazilian scientists in leadership positions in national research institutions have consistently, emphatically, and openly harnessed science to a conservation agenda. In interviews I have carried out among these and other Brazilian environmental scientists over a course of 7 years, I have most consistently heard expressions of a sense of responsibility to make their scientific work relevant to real life problems. While scientists acting as 'policy entrepreneurs' (Kingdon 1985) are a cross-cultural phenomenon, research in different national settings reveal different tendencies or different intensities of the same general tendencies. Brent Steel et al.'s (2001, 2004) research shows American and Canadian scientists to be hesitant (albeit to varying degrees) about engaging with policy processes, and troubled when they do so, and Kenneth Wilkening finds scientists in East Asia to be even less politically active compared to their American and European counterparts (Wilkening 2004). As suggested by studies in other areas (Jasanoff 2005) and by the obvious political engagement on the part of prominent Brazilian scientists described in this study, extending Steel et al.'s line of inquiry to yet other national contexts would likely

\footnotetext{
${ }^{32}$ For an especially powerful argument along these lines, see Sarewitz (2004). See also Lahsen (2004).

${ }^{33}$ Recent experiences of dictatorship might also be relevant historical factor. In Brazil, scientists were important actors in the resistance movement under the dictatorship (1964-1985) and have been venerated for this in subsequent decades. As a result, Brazilian scientists may be less aversive to political engagement, as a whole, compared to countries without similar, recent historical experiences.
} 
yield even more variation in conceptions of the proper relationship between science and policy and, by extension, scientists and decision-makers. ${ }^{34}$

Finally, integrating analysis of the 'cultural match' between emergent norms with foreign origins and domestic practice, such studies can help overcome present limitations in constructivist studies which, lacking a theory of domestic agency, tend to over-predict the influence of international norms in national contexts (Checkel 1997).

In sum, the above analysis suggests the urgency of improving understanding of structural factors and perceptual filters shaping the uptake of science bearing on environmental protection, not the least in the global South, which is home to the largest share of the world's people, land and biodiversity. This case study also supports efforts to counter present trends to substitute politically charged discussion related to justice and equity with techno-scientific and managerial discourses and processes (Brosius 1999). By contrast, it suggests the need to analyze and address the extent to which global inequities in geopolitical power and scientific capacity may reinforce anti-democratic forces and weaken global environmental regimes.

Acknowledgements First and foremost, I wish to thank the scientists and decision makers who made this research possible. I hope to have done justice to their views and positions, and to leave them with the feeling that their participation was worthwhile, even if my interpretations diverge from their own. I am also extremely grateful to a handful of LBA scientists who dedicated time and energy to review versions of this manuscript and provide corrective and illuminating comments, and to Radford Byerly, Jr. for the time and care he put into helping me streamline the manuscript. The initial phase of research for this paper was made possible thanks to the financial support of the National Center for Atmospheric Research and of Sheila Jasanoff at Harvard University through a grant (SBR-9521914) from the Center for Integrated Study of the Human Dimensions of Global Change, a center created through a cooperative agreement between Carnegie Mellon University and the National Science Foundation. The material specifically focused on the LBA is based upon work supported by the National Science Foundation under grants no. 0242042 and 1544589, and by the CLIPORE research program under the Mistra Foundation for Strategic Environmental Research through the Climate Science and Policy Beyond 2012 project. Any opinions, findings, conclusions or recommendations expressed in this material are those of the author and do not necessarily reflect the views of the funding sources. I thank the Energy Planning Program at the Federal University of Rio de Janeiro, Brazil, the Center for Science and Technology Policy Research at the University of Colorado's Center for Cooperative Research in Environmental Sciences (CIRES), and the Brazilian National Institute for Space Research (INPE) for providing institutional home bases and administrational assistance.

\section{References}

Adeodaio S (1990) Amazônia Filtra Gás Carbônico e Melhora a Atmosfera da Terra. J Bras (page number unavailable)

Adler E, Haas P (1992) Conclusion: epistemic communities, world order, and the creation of a reflective research program. Int Organ 46(1):367-390

\footnotetext{
${ }^{34} \mathrm{My}$ research did not reveal such reluctance on the part of Brazilian scientists, as reflected in the fact that a prominent scientist and leader of a federal research center also felt free to engage with environmental activist groups and national and international politics more broadly. This might be a function of the country's past military dictatorship, where scientists took part in the political resistance. Political engagement might also be a response stimulated by the related, relatively more insular political culture, along the lines suggested by Sloan (1984). Further research is necessary, however, to definitively support these tentative hypotheses.
} 
Andreae MO, Artaxo P, Brandão C, Carswell FE, Ciccioli P, da Costa AL, Culf AD, Esteves JL, Gash JHC, Grace J, Kabat P, Lelieveld J, Malhi Y, Manzi AO, Meixner FX, Nobre AD, Nobre C, Ruivo MdLP, Silva-Dias MA, Stefani P, Valentini R, von Jouanne J, Waterloo MJ (2002) Biogeochemical cycling of carbon, water, energy, trace gases, and aerosols in Amazonia: the LBA-EUSTACH experiments. J Geophys Res Atmos 107(D20):8066

Araujo AC, Nobre AD, Kruijt B, Culf AD, Stefani P, Elbers J et al (2002) Dual tower long-term study of carbon dioxide fluxes for a central Amazonian rain forest: the Manaus LBA site. J Geophys Res Atmos 107(D20):8090

Baker TR, Phillips OL, Malhi Y, Almeida S, Arroyo L, Di Fiore A, Higuchi N, Killeen TJ, Laurance SG, Laurance WF, Lewis SL, Monteagudo A, Neill DA, Pitman NCA, Silva N, Vasquez R (2004) Increasing biomass in Amazon forest plots. Philos Trans R Soc Lond B Biol Sci 359:353-365

Barbosa LC (1993) The "greening" of the ecopolitics of the world-system: Amazonia and changes in the ecopolitics of Brazil. J Polit Mil Soc 21(1):107-134

Beck U (1992) The risk society: towards a new modernity. Sage, Newbury Park

Beck U, Giddens A, Lash S (1994) Reflexive modernization: politics, tradition and aesthetics in the modern social order. Stanford University Press, Stanford

Becker BK (2001) Amazonian frontiers at the beginning of the 21st century. In: Hogan DJ, Tolmasquim MT (eds) Human dimensions of global environmental change: Brazilian perspectives. Academia Brasileira de Ciências, Rio de Janeiro, pp 299-323

Benvenuti C (1990) Uma taxa para respirar. Veja 1113:98

Brosius PJ (1999) Green dots, pink hearts: displacing politics from the Malaysian rain forest. Am Anthropol 101(1):36-57

Brown RGE Jr (1996) Environmental science under siege: fringe science and the 104th congress, 23 October, report, Democratic Caucus of the Committee on Science, U.S. House of Representatives. http://www.house.gov/science_democrats/archive/envrpt96.htm. Accessed 10 November 2004

Brown IF, Brilhante SHC, Mendoza E, Oliveira IRd (2002) Estrada de Rio Branco, Acre, Brasil aos Portos do Pacífico: Como maximizar os benefícios e minimizar os prejuízos para o desenvolvimento sustentável da Amazônia Sul-Ocidental. In: Tizón AW, Duarte RSG (eds) La Intergración Regional Entre Bolívia, Brasil y Peru, Seminarios, Mesas Redondas y Conferencias, 25, Lima, Peru, pp 281-296

Capozzoli U (2002) Floresta Ameniza o Aquecimento da Terra. Sci Am Bras 1:30-35

Caropreso A (1990) Amazônia Ajuda a Regular Efeito Estufa. O Estado de São Paulo, 10 October, p 5

Chambers JQ, Tribuzy E, Toledo LC, Crispim BF, Higushi NSJ, Araújo AC et al (2004) Respiration from a tropical forest ecosystem: partitioning of sources and low carbon use efficiency. Ecol Appl Suppl 14(4):S72-S88

Chandler GG (1998) Civil society and development-the role of the third sector in the public policy process in Santa Catarina and Sergipe, Brazil, Doctoral dissertation, Indiana University, Department of Political Science

Checkel J (1997) International norms and domestic politics: bridging the rationalist-constructivist divide. Eur J Int Relat 3(4):473-495

Chou WW, Wofsy SC, Harriss RC, Lin JC, Gerbig C, Sachse GW (2002) Net fluxes of $\mathrm{CO}_{2}$ in Amazonia derived from aircraft observations. J Geophys Res 107(D22):4614

Cloud J (2001) Imaging the world in a barrel: CORONA and the clandestine convergence of the earth sciences. Soc Stud Sci 31(2):231-251

Defries RS, Houghton RA, Hansen M, Field CB, Skole D, Townsend J (2002) Carbon emissions from tropical deforestation and regrowth based on satellite observations for the 1980s and 1990s. Proc Natl Acad Sci 99:14256-14261

Demeritt D (2001) The construction of global warming and the politics of science. Ann Assoc Am Geogr 91(2):307-337

Demeritt D (2006) Science studies, climate change and the prospects for constructivist critique. Econ Soc 35(3):453-479

Dickson D (1989) The new politics of science, 2nd edn. The University of Chicago Press, Chicago

Dunlap RE, Xiao C, McCright AM (2001) Politics and environment in America: partisan and ideological cleavages in public support for environmentalism. Environ Polit 10(4):23-48

Escobar H (2002) Floresta Também Absorve 2 Toneladas de Carbono por Hectare por Ano. O Estado de S. Paulo. http://www-eosdis.ornl.gov/lba_cptec/lba/port/documentos/materias/ 20020219.html. Accessed 31 January 2006 
Fan S, Wofsy S, Bakwin P, Jacob D (1990) Atmosphere-biosphere exchange of $\mathrm{CO}_{2}$ and $\mathrm{O}_{3}$ in the central Amazon forest. J Geophys Res 95:16851

Fan S, Gloor M, Mahlman J, Pacala S, Sarmiento J, Takahashi T, Tans P (1998) A large terrestrial carbon sink in North America implied by atmospheric and oceanic carbon dioxide data and models. Science 282:442-446

Fearnside PM (2001) Saving tropical forests as a global warming countermeasure: an issue that divides the environmental movement. Ecol Econ 39(2):167-184

Fearnside PM (2006) Greenhouse gas emissions from hydroelectric dams: reply to Rosa et al. Clim Change 75:1-2

Fitch JS (1998) The armed forces and democracy in Latin America. Johns Hopkins University Press, Baltimore

Fitzjarrald DR, Moore KE (1990) Mechanisms of nocturnal exchange between the rain forest and the atmosphere. J Geophys Res 9(5):16839-16850

Fogel CA (2002) Greening the earth with trees: science, storylines and the construction of international climate change institutions. Doctoral dissertation, University of California, Santa Cruz

Fogel CA (2004) The local, the global, and the Kyoto Protocol. In: Jasanoff S, Long Martello M (eds) Earthly politics, worldly knowledge: local and global in environmental politics. MIT Press, Cambridge, pp 103-125

Fogel CA (2007) Constructing progressive climate change norms: the US in the early 2000s. In: Pettinger M (ed) Social construction of climate change. Ashgate, Surrey, pp 99-120

Friedman EJ, Hochstetler K (2002) Assessing the third transition in Latin American democratization: representational regimes and civil society in Argentina and Brazil. Comp Polit 35(1): $21-42$

Friedman EJ, Hochstetler K, Clark AM (2001) Sovereign limits and regional opportunities for global civil society in Latin America. Lat Am Res Rev 36(3):7-35

Funtowicz S, Ravetz J (1992) Three types of risk assessment and the emergence of postnormal science. In: Krimsky S, Golding D (eds) Social theories of risk. Praeger, Westport, pp 215-228

Gelbspan R (1997) The heat is on: the high stakes battle over Earth's threatened climate. AddisonWesley, New York

Goldemberg J (1994) The road to Rio. In: Mintzer IM, Leonard JA (eds) Negotiating climate change: the inside story of the Rio convention. Cambridge University Press, Cambridge, pp 175-186

Goulden ML, Munger J, Fan S-M, Daube BC, Wofsy SC (1996) Measurements of carbon sequestration by long-term eddy covariance: methods and a critical evaluation of accuracy. Glob Chang Biol 2:169-182

Grace J, Lloyd J, McIntyre J, Miranda AC, Meir P, Miranda HS, Nobre C, Moncrieff J, Massheder J, Malhi Y, Wright I, Gash J (1995) Carbon dioxide uptake by an undisturbed tropical rain forest in southwest Amazonia, 1992 to 1993. Science 270:778-780

Guérin F, Abril G, Junet A, de Bonnet M-P (2008) Anaerobic decomposition of tropical soils and plant material. Appl Geochem 23:2272-2283

Guérin F, Abril G, Richard S, Burban B, Reynouard C, Seyler P, Delmas R (2006) Methane and carbon dioxide emissions from tropical reservoirs: significance of downstream rivers. Geophys Res Lett 33:L21407

Guimarães RP (1991) The ecopolitics of development in the third world: politics and environment in Brazil. Lynne Rienner, Boulder

Guimarães RP (2002) The bureaucratic politics of environmental policy formation in Brazil. In: Nagel SS (ed) Environmental policy and developing nations. McFarland, London, pp 227-244

Haas PM (1989) Do regimes matter? Epistemic communities and Mediterranean pollution control. Int Organ 43(3):1-35

Haas PM (1990) Saving the Mediterranean. Columbia University Press, New York

Haas PM (1992) Introduction: epistemic communities and international policy coordination. Int Organ 46(1):1-35

Hansen B (1998) Is $\mathrm{CO}_{2}$ your friend? Keep burning fossil fuels, group says. Colorado Daily 1:3

Hecht SB, Cockburn A (1989) Fate of the forest: developers, destroyers, and defenders of the Amazon. Verso, London

Hurrell A (1992) Brazil and Amazonian deforestation. In: Hurrell A, Kingsbury B (eds) The international politics of the environment: actors, interests, and institutions. Clarendon, Oxford, pp 398-429 
Hurrell A (2005) The United States and Brazil: comparative reflections. In: Hirst M (ed) The United States and Brazil: a long road of unmet expectations. Routledge, New York, pp 73-107

Intergovernmental Panel on Climate Change (2000) Special report on land use, land use change, and forestry. Cambridge University Press, Cambridge

Jakobsen S (2000) Transnational environmental groups, media science and public sentiment(s) in domestic policy-making on climate change. In: Higgot R, Underhill G, Bieler A (eds) Non-state actors and authority in the global system. Routledge, New York, pp 274-289

Jasanoff S (1990) The fifth branch: science advisors as policymakers. Harvard University Press, Cambridge

Jasanoff S (2004) The idiom of co-production. In: Jasanoff S (ed) States of knowledge: the coproduction of science and social order. Taylor \& Francis, New York, pp 1-12

Jasanoff S (2005) Designs on nature: science and democracy in Europe and the United States. Princeton University Press, Princeton

Jasanoff S, Wynne B (1998) Science and decision-making. In: Rayner S, Malone EL (eds) Human choice and climate change, vol 1. Battelle, Columbus, pp 1-87

Jasanoff S, Markle GE, Petersen JC, Pinch T (eds) (1995) Handbook of science and technology studies. Sage, London

Jornal do Brasil (2002) Amazonia Elimina Gas que a Selva Produz. 5 August, p A4

Kaiser J (1998) Possibly vast greenhouse gas sponge ignites controversy. Science 282:386-387

Kingdon JW (1985) Agendas, alternatives, and public policies. Little Brown, Boston

Lahsen M (1999) The detection and attribution of conspiracies: the controversy over Chapter 8. In: Marcus GE (ed) Paranoia within reason: a casebook on conspiracy as explanation. University of Chicago Press, Chicago, pp 111-136

Lahsen M (2004) Transnational locals. In: Jasanoff S, Long Martello M (eds) Earthly politics, worldly knowledge: local and global in environmental politics. MIT Press, Cambridge, pp 151-172

Lahsen M (2005a) Seductive simulations: observations of efforts to box earth epistemological quandaries and anthropological observations of efforts to box earth. Soc Stud Sci 35: 895-922

Lahsen M (2005b) Technocracy, democracy and U.S. climate science politics: the need for demarcations. Sci Technol Human Values 30(1):137-169

Lahsen M (2007) Distrust and participation in international science and environmental decision making: knowledge gaps to overcome. In: Pettinger M (ed) The social construction of climate change. Ashgate, Surrey, pp 173-196

Lahsen M (2008) Experiences of modernity in the greenhouse: a cultural analysis of a physicist 'trio' supporting the conservative backlash against global warming. Glob Environ Change 18: 204-209

Lahsen M, Nobre CA (2007) The challenge of connecting international science and local level sustainability: the case of the LBA. Environ Sci Policy 10(1):62-74

Lahsen M, Öberg G (2006) The role of unstated mistrust and disparities in scientific capacity. Report published by The Swedish Institute for Climate Science and Policy Research, Linköbing University, Sweden, 2006. http://sciencepolicy.colorado.edu/admin/publication_files/ resource-2565-2006.19.pdf

Lash S, Szerszynski B, Wynne B (eds) (1996) Risk, environment and modernity: towards a new ecology. Sage, London

Laurance WF, Cochrane MA, Bergen S, Fearnside PM, Delamônica P, Barber C, D'Angelo S et al (2001) The future of the Brazilian Amazon. Science 291(5503):438-439

LBA Science Planning Group (1996) The large-scale biosphere-atmosphere experiment in Amazonia (LBA): concise experimental plan

Litfin KT (1994) Ozone discourses: science and politics in global environmental cooperation. Columbia University Press, New York

Lorenzi R (2005) Plants may not mitigate global warming. Discovery channel on-line. http://dsc.discovery.com/news/briefs/20050829/co2.html. Accessed 17 February 2006

MacDonald GJ, Nielson DL, Stern MA (1997) Latin American environmental policy in international perspective. Westview, Boulder

Malhi Y, Phillips O (2004) Tropical forests and global atmospheric change: a synthesis. Phil Trans R Soc Lond B Biol Sci 359:309-310

Malhi Y, Nobre AD, Grace J, Kruijt B, Pereira MGP, Culf A, Scott S (1998) Carbon dioxide transfer over a Central Amazonian rain forest. J Geophys Res Atmos 103:31593-31612

Martins Filho J, Zirker D (2000) Nationalism, national security and Amazônia: military perceptions and attitudes in contemporary Brazil. Armed Forces Soc 27(1):105-129 
McNie E (2007) Reconciling the supply of scientific information with user demands: an analysis of the problem and review of the literature. Environ Sci Policy 10(1):17-38

Menezes A (2006) Brasil Pode Lucrar Com o Seqüestro de Carbono. A Crítica. http://www.amazonia. org.br/negocios/index.cfm?fuseaction=noticia\&id=194790. Accessed 30 January 2006

Miller SD, Goulden ML, Menton MC, Rocha HRd, Freitas HCd, Michela A et al (2004) Biometric and micrometeorological measurements of tropical forest carbon balance. Ecol Appl 14(4):S114 S126

Mooney C (2005) Mann hunt. In: Prospect, 5 June. Retrieved from http://www.prospect.org/ web/page.ww? section $=$ root\&name $=$ ViewWeb\&articleId $=9932$

Mumme SP, Korzetz E (1997) Democratization, politics, and environmental reform. In: MacDonald et al (eds) Latin American environmental policy in international perspective. Westview, Boulder

Nemani RR, Keeling CD, Hashimoto H, Jolly WM, Piper SC, Tucker CJ, Myneni RB, Running SW (2003) Climate-driven increases in global terrestrial net primary production from 1982 to 1999. Science 300:1560-1563

Nobre CA (2003) Florestas Tropicais e o Protocolo de Quioto. O Estado de São Paulo. http://www. amazonia.org.br/compradores/opiniao/print.cfm?id=73180. Accessed 20 January 2005

O Liberal (1999) LBA Reúne Cientistas em Belém. 25 May, 11

Ometto JPHB, Nobre AD, Rocha HR, Artaxo P, Martinelli LA (2005) Amazonia and the modern carbon cycle: lessons learned. Oecologia 143(4):483-500

Persson M, Azar C (2004) Brazil beyond Kyoto: prospects and problems in handling tropical deforestation in a second commitment period. http://www.naturvardsverket.se/dokument/ press/2004/juni/postkyoto/brazil1.pdf. Chalmers University of Technology

Potter C, Genovese VB, Klooster S, Bobo M, Torregrosa A (2001) Biomass burning losses of carbon estimated from ecosystem modeling and satellite data analysis for the Brazilian Amazon Region. Atmos Environ 35:1773-1781

Província de Belém (1999) Projeto vai orientar decisões sobre a floresta. http://lba.cptec.inpe.br/ lba/img/jornal_3.gif, 25 May. Accessed 18 February 2006

Rede Globo (2002) Pesquisadores Do Mundo Inteiro Discutem o Papel Da Floresta Amazônica Nas Mudanças Do Clima. Globo News Network (Globo Rede). http://www-eosdis.ornl. gov/lba_cptec/lba/port/documentos/materias/20020708.html. Accessed 31 January 2006

Román M, Carson M (2009) Sea change: US climate policy prospects under the Obama Administration. The Commission on Sustainable Development, Stockholm. http://www.regeringen. se/content/1/c6/12/39/02/abbc3b90.pdf

Saleska SR, Miller S, Matross D, Goulden M, Wofsy S, da Rocha H, de Camargo P, Crill P, Daube B, de Freitas H, Hutyra L, Keller M, Kirchhoff V, Menton M, Munger J, Pyle E, Rice A, Silva H (2003) Carbon in Amazon forests: unexpected seasonal fluxes and disturbanceinduced losses. Science 302(5650):5154-1557. On-line supplement accessible at: http://www. sciencemag.org/cgi/content/full/302/5650/1554/DC1

Santilli M (2005) Tropical deforestation and the Kyoto Protocol. Clim Change 71(3):267-276

Santilli M, Moutinho P, Schwartzman S, Nepstad D, Curran L, Nobre C (2003) Tropical deforestation and the Kyoto Protocol. Proposal presented at the ninth meeting of the conference of the parties in Milan, Italy

Sarewitz D (2004) How science makes environmental controversies worse. Environ Sci Policy 7: 385-403

Schmink M, Wood CH (1992) Contested frontiers in Amazonia. Columbia University Press, New York

Schneider SH (2000) Is the "citizen-scientist" an oxymoron? In: Kleinman D (ed) Beyond the science wars: science, technology and democracy. State University of New York Press, Albany, pp 103-120

Silveira V (2002a) Pesquisa Comprova Ajuda da Floresta Contra Efeito Estufa. Gazeta Mercantil, 2 July, p C6

Silveira V (2002b) Pesquisas Para Medir Quanto as Florestas Absorbem de Carbono. Gazeta Mercantil, 30 Oct, p C4

Skolnikoff E (1993) The elusive transformation: science, technology, and the evolution of international relations. Princeton University Press, Princeton

Sloan JW (1984) Public policy in Latin America. University of Pittsburgh Press, Pittsburgh

Steel B, Lach D, List P, Shindler B (2001) The role of scientists in the natural resource and environmental policy process: a comparison of Canadian and American publics. J Environ Syst 28(2):113-155 
Steel B, List P, Lach D, Shindler B (2004) The role of scientists in the environmental policy process: a case study from the American West. Environ Sci Policy 7:1-13

Steinberg PF (2001) Environmental leadership in developing countries: transnational relations and biodiversity policy in Costa Rica and Bolivia. MIT Press, Cambridge

Tabak I (2005) Um Conflito Amazônico. Jornal Do Brasil, 27 February, A3

Vianna Rodrigues RL (2004) Análise Dos Fatores Determinantes Do Desflorestamento Na Amazônia Legal, Doctoral Dissertation, Coordenação Dos Programas De Pós-Graduação De Engenharia (COPPE), Universidade Federal Do Rio De Janeiro, Brazil

Wiarda HJ (1990) The democratic revolution in Latin America: history, politics, and U.S. Policy. Holmes \& Meier, New York

Wiarda HJ, Kline HF (2000) Latin American politics and development. Westview, Boulder

Viola E (2004a) Brazil in the politics of global governance and climate change, 1989-2003. Working Paper Number CBS-56-04, Centre for Brazilian Studies, Oxford University. http://www.brazil. ox.ac.uk/workingpapers/Eduardo\%20Viola\%2056.pdf. Accessed 4 October 2004

Viola E (2004b) A evolução do papel do Brasil no regime internacional de mudança climática e na governabilidade global. Cena Internacional 6(1)

Wilkening KE (2004) Localizing universal science: acid rain science and policy. In: Harrison NE, Bryner GC (eds) Science and politics in the international environment. Rowman and Littlefield, Lanham, pp 209-240

Wood CH, Schmink M (1993) The military and the environment in the Brazilian Amazon. J Polit Mil Soc 21(1):81-105 